\title{
Mirror exposure to increase body satisfaction: Should we guide the focus of attention towards positively or negatively evaluated body parts?
}

Citation for published version (APA):

Jansen, A., Voorwinde, V., Hoebink, Y., Rekkers, M., Martijn, C., \& Mulkens, S. (2016). Mirror exposure to increase body satisfaction: Should we guide the focus of attention towards positively or negatively evaluated body parts? Journal of Behavior Therapy and Experimental Psychiatry, 50, 90-96. https://doi.org/10.1016/j.jbtep.2015.06.002

Document status and date:

Published: 01/03/2016

DOI:

10.1016/j.jbtep.2015.06.002

Document Version:

Publisher's PDF, also known as Version of record

Document license:

Taverne

Please check the document version of this publication:

- A submitted manuscript is the version of the article upon submission and before peer-review. There can be important differences between the submitted version and the official published version of record.

People interested in the research are advised to contact the author for the final version of the publication, or visit the DOI to the publisher's website.

- The final author version and the galley proof are versions of the publication after peer review.

- The final published version features the final layout of the paper including the volume, issue and page numbers.

Link to publication

\footnotetext{
General rights rights.

- You may freely distribute the URL identifying the publication in the public portal. please follow below link for the End User Agreement:

www.umlib.nl/taverne-license

Take down policy

If you believe that this document breaches copyright please contact us at:

repository@maastrichtuniversity.nl

providing details and we will investigate your claim.
}

Copyright and moral rights for the publications made accessible in the public portal are retained by the authors and/or other copyright owners and it is a condition of accessing publications that users recognise and abide by the legal requirements associated with these

- Users may download and print one copy of any publication from the public portal for the purpose of private study or research.

- You may not further distribute the material or use it for any profit-making activity or commercial gain

If the publication is distributed under the terms of Article $25 \mathrm{fa}$ of the Dutch Copyright Act, indicated by the "Taverne" license above, 


\title{
Mirror exposure to increase body satisfaction: Should we guide the focus of attention towards positively or negatively evaluated body parts?
}

\author{
Anita Jansen ${ }^{\mathrm{a}}{ }^{*}$, Vera Voorwinde ${ }^{\mathrm{b}}$, Yvette Hoebink ${ }^{\mathrm{b}}$, Marlies Rekkers ${ }^{\mathrm{c}}$, \\ Carolien Martijn ${ }^{\mathrm{a}}$, Sandra Mulkens ${ }^{\mathrm{a}, \mathrm{d}}$ \\ ${ }^{a}$ Clinical Psychological Science, Maastricht University, The Netherlands \\ ${ }^{\mathrm{b}}$ Health \& Social Psychology Master, Maastricht University, The Netherlands \\ ${ }^{\mathrm{c}}$ Maatschap De Praktijk, Amsterdam, The Netherlands \\ ${ }^{\mathrm{d}}$ Virenze Riagg Maastricht, The Netherlands
}

\section{A R T I C L E I N F O}

\section{Article history:}

Received 22 August 2014

Received in revised form

9 June 2015

Accepted 13 June 2015

Available online 17 June 2015

\section{Keywords:}

Body image

Mirror exposure

Body exposure

Attention

Eating disorders

Body dissatisfaction

Cognitive behaviour therapy

\begin{abstract}
A B S T R A C T
Background and Objectives: Though there is some evidence that body exposure increases body satisfaction, it is still unclear why exposure works and how attention should be guided during exposure. This pilot study manipulates the focus of attention during body exposure.

Methods: Female participants high in body dissatisfaction were randomly assigned to an exposure intervention that exclusively focused on self-defined attractive $(n=11)$ or self-defined unattractive $(n=11)$ body parts. Both interventions consisted of five exposure sessions and homework. Outcome and process of change were studied.

Results: Both types of exposure were equally effective and led to significant improvements in body satisfaction, body checking, body concerns, body avoidance and mood at post-test. Improvements for body satisfaction and mood were maintained at follow-up while body shape concerns and body checking still improved between post-test and follow-up. Body avoidance improvements were maintained for the positive exposure while the negative exposure tended to further decrease long-term body avoidance at follow-up.. The 'positive' exposure induced positive feelings during all exposure sessions while the 'negative' exposure initially induced a worsening of feelings but feelings started to improve after some sessions. The most unattractive body part was rated increasingly attractive in both conditions though this increase was significantly larger in the negative compared to the positive exposure condition.

Limitations: The sample size was small and non-clinical.

Conclusions: Both types of exposure might be effective and clinically useful. Negative exposure is emotionally hard but might be significantly more effective in increasing the perceived attractiveness of loathed body parts and in decreasing avoidance behavior.
\end{abstract}

๑) 2015 Elsevier Ltd. All rights reserved.

\section{Introduction}

Body dissatisfaction is involved in the development, maintenance and relapse of eating disorders (Johnson \& Wardle, 2005; Stice \& Shaw, 2002). To increase body satisfaction, exposure is more and more used as part of eating disorder treatments. Studies

\footnotetext{
* Corresponding author. Clinical Psychological Science, Faculty of Psychology and Neuroscience, Maastricht University, P.O. Box 616, 6200 MD, Maastricht, The Netherlands.

E-mail address: a.jansen@maastrichtuniversity.nl (A. Jansen).
}

show that mirror exposure increases body satisfaction of patients with anorexia nervosa (Key et al., 2002), normal weight eating disorder patients (Hildebrandt, Loeb, Troupe, \& Delinsky, 2012), severely obese adolescents (Jansen et al., 2008), normal weight and overweight binge eaters (Hilbert, Tuschen-Caffier, \& Vögele, 2002) and body dissatisfied students (Luethcke, McDaniel, \& Becker, 2011; Moreno-Domínguez, Rodríguez-Ruiz, Fernández-Santaella, Jansen, \& Tuschen-Caffier, 2012). These studies also show that body exposure can be done in several ways; it is still unclear how a good exposure should be done, and why it should be done that way. Some studies demonstrate the effectiveness of non-judgmental 
acceptance based exposure (Delinsky \& Wilson, 2006; Hildebrandt et al., 2012; Trentowska, Svaldi, \& Tuschen-Caffier, 2014 - though this latter study did not have a control condition), while others (Moreno-Domínguez et al., 2012) found that a focus on one's body while expressing the related feelings and thoughts elicited is more effective to increase body satisfaction than the non-judgmental describing of one's own body.

In an experimental eye-tracking study (Jansen, Nederkoorn, \& Mulkens, 2005), we found that a healthy way of looking at one's own body is opposite to what most body dissatisfied patients do: While eating disorder patients focused on their self-defined negatively evaluated body parts during short exposure to pictures of their own body, healthy participants did exactly the opposite and focused on the own body parts that they had evaluated as most attractive. Moreover, providing evidence for a causal relationship between selective visual attention and body dissatisfaction, we found that the experimental manipulation of such an attentional bias towards negatively evaluated body parts in healthy students induced body dissatisfaction whereas the manipulation of a bias towards positively evaluated body parts increased body satisfaction in nonclinical body dissatisfied students (Smeets, Jansen, \& Roefs, 2011). Translation of these experimental findings might mean that body exposure will be particularly effective when it induces an attentional bias towards body parts that are positively evaluated. Inducing such an attention bias might be considered the learning of a 'healthy' viewing pattern. In the present study, we compare the effectiveness of a body exposure intervention that is exclusively directed at body parts that are evaluated as most attractive vs. a body exposure intervention that is exclusively directed at body parts that are evaluated as most unattractive. It is hypothesized that focusing one's attention towards the most positively evaluated body parts will lead to a significantly stronger increase in body satisfaction and mood compared to focusing on the most negatively evaluated body parts. To also study the process of change, participants repeatedly rated their feelings during the exposure sessions and they also evaluated the attractiveness of their most extremely evaluated body parts (most unattractive and most attractive) after each session.

\section{Method}

\subsection{Participants}

First-year psychology students of Maastricht University voluntarily take part in an elaborate screening session at the beginning of each academic year. The Dutch questionnaire "My Looks" (Bouman, 1999), measuring body dissatisfaction (higher scores mean more body dissatisfaction), is part of this screening. The $20 \%$ highest female scorers with a self-reported Body Mass Index (BMI) between 19 and 27 were invited to take part in a training to improve body satisfaction. During screening interviews, it appeared that of the 27 interested students, five participants were not suitable to take part: four of them expressed no severe body dissatisfaction at the time of the interview and one participant was seriously depressed (BDI score $>30$ ) and referred to mental health care. The remaining 22 female students were randomly assigned to the positive $(n=11)$ vs. negative exposure $(\mathrm{n}=11)$. Mean age was 19.8 yrs $(\mathrm{SD}=1.5$, range 18-23) and mean BMI (measured at pre-test) was 23.5 ( $\mathrm{SD}=2.4$, range 18-29). Two persons had a BMI $>27: 27.2,29.0$, pointing to a discrepancy between their self-reported weight/height and the measured weight/height. We decided to include these participants in the study. There were no significant differences in age $(t$ $(20)=1.1, N S)$ and BMI $(t(20)=1.3, N S)$ between both interventions. Participants received course credits or a $€ 20$ gift voucher for participation. The study was approved by the ethical committee of the Psychology department.

\subsection{Design and interventions}

All participants were treated individually by one of two female therapists (VV, YH) who each performed $50 \%$ of both exposure types. Exposure training and supervision were provided by cognitive behaviour therapists (SM, AJ). Both conditions consisted of a pre-session including pre-measurements, five exposure sessions, a post measurement and a follow-up. All sessions, except for the follow-up, took place within 3 weeks. Pre-measurements were done in the pre-session, post-measurements were done directly after the 5th exposure session. The follow-up measurement was one month after the post measurement. After the follow-up measurement, the participant was debriefed and received compensation. There were no drop-outs, all 22 participants completed all sessions.

\subsubsection{Pre-session}

In the pre-session, informed consent was signed, several questionnaires (see assessment) were completed and body weight and height were measured. Then 33 body parts were rated by the participant from 0 ("very unattractive") to 10 ("very attractive") and, depending on the condition, a hierarchy of either the 8 most attractive or the 8 most unattractive body parts was drawn up. To make the hierarchy, it was asked "for which of the body parts would it be the least difficult to look at and to talk about?" followed by "for which of the remaining body parts would it be the least difficult to look at and to talk about?" and so on.

After that, the rationale of the exposure was explained. Participants in the positive exposure condition were shown studies indicating that selective attention for negative body parts is related to body dissatisfaction while a focus on positive body parts is related to an increase in body satisfaction (Jansen et al., 2005; Smeets et al., 2011). It was explained that the goal of 'positive exposure' is to induce an attentional focus on positive body parts that, in the long run, should become more automatic and habitual. Participants in the negative exposure condition were explained that habituation to negative feelings without avoidance is necessary to increase body satisfaction. It was clarified that one usually avoids prolonged exposure to the body because of unpleasant feelings while prolonged exposure is necessary for the negative feelings to extinguish. The participants rated their expectations of the intervention (see assessment) and appointments for the 5 exposure sessions were made.

\subsubsection{Exposure sessions}

The intervention consisted of 5 individual exposure sessions within 3 weeks. The actual exposure in each session lasted $30 \mathrm{~min}$; before and after the actual exposure, homework assignments were discussed. Participants in the positive exposure condition were exposed to their 8 self-defined most attractive body parts, participants in the negative exposure condition were exposed to their 8 self-defined most unattractive body parts. In every exposure session 2 body parts from the hierarchy were principally addressed, starting with the least difficult parts and building up to he two most difficult body parts from the hierarchy (in the last session). Flexibly switching back to previous body parts or moving on to a next one was allowed throughout all exposure sessions. In the last exposure session all 8 selected body parts were repeated. During the first exposure session, in vitro exposure took place: without a mirror and fully dressed. The participant was mentally exposed to her own body, being guided by the therapist to think of and talk about two specific body parts. After the $30 \mathrm{~min}$ in vitro exposure, homework was agreed upon and the participant was prepared for the next four in vivo sessions. In each of the next four sessions, $30 \mathrm{~min}$ of in vivo exposure was carried out. The participant stood before a large, full- 
length mirror while wearing underwear or a bikini. A second large mobile mirror could be used to look at the body from different angles. The therapist, standing left or right of the participant, a bit behind her, guided the direction of the participant's attention while the participant was continuously looking in the mirror.

In the positive exposure condition the participant focused on her most attractive body parts. She was taught to talk in a selfenhancing positive way about her body; she described the beauty of the body parts, without using any diminutives, devaluations, negative words and refraining from putting positive descriptions too much into perspective or nuancing. She had to talk about her body in the first person, in a positive way without watering down what was being said. Participants were asked to reformulate their sentences if they broke these rules. The therapist, standing left or right of the participant, a bit behind her, guided the direction of the participant's attention while the participant was continuously looking in the mirror. The participant was continually reinforced by the therapist for looking at and talking about the body parts in this positive self-serving way. Homework assignments (see homework) stimulated the use of an extensive vocabulary to describe the beauty of body parts. When participants ran out of ideas they were suggested to talk positively about other, not yet mentioned aspects like shape, function, color, size, symmetry, health or feel of the body part. They were repeatedly asked to summarize what they said about a specific body part and in the end they assigned a positive word to the body part that best described it (e.g., athletic, smooth, sparkling). Then they moved on to the next body part for which the same procedure was carried out.

In the negative exposure condition the participant focused on her most unattractive body parts. She was instructed to keep looking at her body, to describe the body part and to speak out loudly the thoughts and feelings that were elicited by the exposure. She was instructed not to avoid or turn-off the feelings by thinking of something else or looking away (distraction) but to just let the thoughts and feelings come up and be. Feelings were summarized recurrently into one emotion that best described the way she perceived her body. Homework assignments (see homework) stimulated the use of an extensive vocabulary to describe the own body and associated emotions.

\subsubsection{Homework}

Homework assignments for both types of exposure always included practicing the exposure of the session at home. In addition, participants in the positive exposure condition were given the following homework assignments: After session 1: write down 30 synonyms for the word "beautiful", after session 2: give positive evaluations of your 8 body parts and a reason for these evaluations, e.g., "I like my shoulders because they are beautifully symmetrical" and think of 10 positive sentences about your appearance, like "I do look good". After session 3: make a 'positive mirror'; plaster a mirror with pictures, photo's and/or text messages that give you a good feeling about your body. After session 4: make a collage of media models and indicate in what respect you are more beautiful than the models (session 4).

Homework assignments for the negative exposure: after session 1: write down 30 words, including synonyms, for different feelings, after session 2: evaluate your 8 body parts and give a reason for this evaluation, e.g., "I loathe my legs because they are too short and fat" and think of 10 sentences that describe the emotions that come up when looking at your body, like "my belly is disgusting, I feel very sad when I see all this plump belly fat", after session 3: make a 'body mirror'; plaster a mirror with pictures, photo's and/or text messages related to your body, and after session 4: make a collage of pictures of your body, and use pictures you are not happy with. The homework was checked by the therapists and shortly discussed within the sessions.

\subsection{Assessment: Outcome}

Expectations of the training. Participants rated their expectations of the training on a 9 point scale (from 1 - 'not at all' to $9-$ 'extremely'; higher scores meaning more positive expectations) for the following questions: 1) How credible is this training for you? 2) How confident are you that this training will help you to reduce your body dissatisfaction? 3) Would you advise this training to a friend with comparable problems? A mean expectation score was calculated, of which the internal consistency was very good, Cronbach's $\alpha=0.88$.

Body satisfaction was measured by a rating between 0 (very negative) and 10 (very positive) for the own body. Higher scores indicate more body satisfaction.

Body shape concerns were measured with the body shape concerns subscale of the eating disorder examination (EDEQ; Fairburn \& Beglin, 1994). The subscale contains 8 items that measure body shape concerns in the past 28 days which are scored on a 7-point scale ranging from 0 ('not at all') to 6 ('extremely'). Its internal consistency was very good: Cronbach's $\alpha=0.89$. Higher scores indicate more body shape concerns.

Body checking was measured with the body checking questionnaire (BCQ; Reas, Whisenhunt, Netemeyer, \& Williamson, 2002). The 23 items are scored on a 5-point Likert scale range from 1 ('never') to 5 ('very often'). The internal consistency of the BCQ was very good, Cronbach's $\alpha=0.85$. A sum score was calculated; higher scores indicate more body checking.

Body image avoidance, i.e. the tendency to avoid the confrontation with one's own body image, was measured with the body image avoidance questionnaire (BIAQ; Rosen, Strebnik, Saltzberg, \& Wendt, 1991). The questionnaire contains 19 items that are scored on a 6-point Likert scale ranging from 0 ('never') to 5 ('always'), higher scores indicating more body avoidance. The internal consistency of the BIAQ was acceptable, Cronbach's $\alpha=0.76$.

Mood was measured with Beck's depression inventory II (BDI-II; Beck, Steer, \& Brown, 2002). The BDI consists of 21 items that are scored on a 4-point Likert scale ranging from 0 to 3. At pre-test the internal consistency of the BDI was questionable, while Cronbach's $\alpha$ at posttest and follow-up were respectively acceptable and good (pre-test $\alpha=0.68$, post-test $\alpha=0.78$, follow-up $\alpha=0.85$ ). A higher score indicates an increasingly depressed mood.

All questionnaires were delivered and completed in Dutch. The Visual Analogue Scales were made in Dutch, the EDEQ, BCQ and BIA were translated by the first author in consultation with other researchers in our lab. The translated Dutch versions were then back translated in English by native speakers in our lab and adaptations were made if needed. The Dutch version of the BDI-II was used (Van der Does, 2002). This Dutch version has been tested as reliable and valid (Evers, Vliet-Mulder, \& Groot, 2005).

\subsection{Assessment: Process of change}

During the exposure sessions, participants rated their feelings every $5 \mathrm{~min}$ and at the end of each exposure session (as well as at pre-test, post-test and follow-up) they rated the perceived attractiveness of their own self-identified most attractive and most unattractive body parts.

State feelings (stress, depression, anxiety, attractiveness and satisfaction with the body) were assessed every 5 min (minute 0,5 , $10,15,20,25,30$ ) during the exposures on $100 \mathrm{~mm}$ visual analogue scales (VAS). A mean VAS score was calculated ranging from 0 (very negative feelings) to 100 (very positive feelings) for each time of measurement.

Perceived attractiveness of the most extremely evaluated body parts. For each individual, a most attractive and a most unattractive 
body part were identified in the pre-session during the making of a body part hierarchy. At the end of each exposure session, the participant rated the attractiveness of her (self-defined) most attractive and her (self-defined) most unattractive body part ( 0 = very unattractive, $100=$ very attractive $)$.

\subsection{Statistical analyses}

The data were analysed with three mixed (multivariate) ANOVAs. The first MANOVA analysed the effect of the interventions on the main dependent variables (body satisfaction scales and depression). The second ANOVA examines the course of feelings during the exposures. The third ANOVA examines the perceived attractiveness of extremely evaluated body parts during the exposures. Any significant interactions are broken down using univariate tests and/or planned contrasts using Bonferroni correction.

\section{Results}

\subsection{Credibility of intervention}

Participants in the positive exposure intervention $(M=6.2$, $S D=1.3)$ and the negative exposure intervention $(M=6.7, S D=1.4)$ did not differ in their expectations of the intervention $(t(20)<1)$.

\subsection{Outcome: Body satisfaction and depression}

Table 1 shows the data. A 2 (Intervention: positive vs. negative exposure) x 3 (Time: pre-test vs. post-test vs. follow up) repeated measures MANOVA was conducted to test intervention effects on body satisfaction (body satisfaction rating, body shape concerns, body checking, body avoidance) and depression. The results showed a significant main effect of Time, $F(10,74)=5.54, p<0.001$, $\eta^{2}=0.43$, no main effect of Intervention, $F(5,16)=1.59, p=0.22$, $\eta^{2}=0.33$, and no significant Intervention $\times$ Time interaction effect, $F(10,74)=0.79, p=0.64, \eta^{2}=0.1$, indicating that both interventions were effective in increasing body satisfaction and reducing depression, and that they did not differ in their effectiveness. The univariate tests showed significant effects of time on all variables: $F(2,40)=14.6, p<0.001, \eta^{2}=0.42$ for body satisfaction ratings, $F(2,40)=22.8, p<0.001, \eta^{2}=0.53$ for body shape concerns, $F(2,40)=12.4, p<0.001, \eta^{2}=0.38$ for body checking, $F$ $(2,40)=12.96, p<0.001, \eta^{2}=0.39$ for body avoidance, and $F$ $(2,40)=24.3, p<0.001, \eta^{2}=0.55$ for depression. Within subjects contrasts showed significant main effects of time between pre-test and post-test for all variables (body satisfaction rating $F$ $(1,20)=13.8, p=0.001, \eta^{2}=0.41$; body shape concerns $F$

\section{Table 1}

Pre-, post-, and follow-up (FU) means (M) and standard deviations (SD) for the positive exposure intervention (POS) and the negative exposure intervention (NEG). EDEQ-SC = Shape Concerns subscale of the Eating Disorder Examination Questionnaire; $\mathrm{BCQ}=$ Body Checking Questionnaire; BIAQ = Body Image Avoidance Questionnaire; BDI = Beck Depression Inventory II. All means and SDs in this table should be arranged below each other in the middle of each cell: $M(S D)$.

\begin{tabular}{llccc}
\hline Measure & Intervention & PRE & POST & \multicolumn{1}{l}{ FU } \\
\hline \multirow{2}{*}{ Body satisfaction rating } & POS & $4.8(1.2)$ & $5.9(1.3)$ & $6.0(1.1)$ \\
& NEG & $6.1(0.9)$ & $6.7(0.8)$ & $6.8(0.8)$ \\
EDEQ-SC & POS & $3.4(1.4)$ & $2.6(1.4)$ & $2.1(1.5)$ \\
& NEG & $2.7(1.4)$ & $1.9(1.2)$ & $1.3(1.1)$ \\
BCQ & POS & $57.8(11.1)$ & $51.5(12.0)$ & $49.3(11.5)$ \\
& NEG & $51.9(11.5)$ & $48.4(7.0)$ & $42(7.5)$ \\
BIAQ & POS & $30.5(10.6)$ & $25.8(8.1)$ & $26.2(10.1)$ \\
& NEG & $27.0(4.9)$ & $24.8(6.1)$ & $21.8(6.7)$ \\
BDI & POS & $15.4(5.3)$ & $9.1(6.2)$ & $8.9(6.4)$ \\
& NEG & $11.7(4.3)$ & $5.9(3.6)$ & $5.7(3.8)$ \\
\hline
\end{tabular}

$(1,20)=13.97, p=0.001, \eta^{2}=0.41$; body checking $F(1,20)=6.2$, $p=0.021, \eta^{2}=0.24$; body avoidance $F(1,20)=10.69, p=0.004$, $\eta^{2}=0.35$, and depression $\left.F(1,20)=45.2, p<0.001, \eta^{2}=0.69\right)$. Body shape concerns, $F(1,20)=14.4, p=0.001, \eta^{2}=0.42$, and body checking, $F(1,20)=10.7, p=0.004, \eta^{2}=0.35$, also showed a significant decrease between posttest and follow up, meaning that there was still improvement between post-test and follow up, while body satisfaction rating $(F<1)$, body avoidance $(F=2.3$, $\left.p=0.15, \eta^{2}=0.1\right)$ and depression $(F<1)$ did not, meaning that improvements were maintained. The Time $\times$ Intervention contrasts showed no differences between groups in change between pre-test and post-test, on none of the variables. Between post-test and follow-up no Time $\times$ Intervention effects were found for body satisfaction ratings $(F<1)$, body concerns $(F<1)$, body checking $(F=2.4$, NS) and depression $(F<1)$. Body avoidance however showed a marginally significant Time $\times$ Intervention effect, $F=3.7$, $p=0.067, \eta^{2}=0.16$, indicating a marginal differential change in body avoidance between post measure and follow up between interventions. Table 1 shows that body avoidance remains the same between post measure and follow-up in the positive exposure intervention, while it tended to further decrease between post measure and follow up in the negative avoidance intervention.

\subsection{Process of change: Course of feelings during exposure}

Fig. 1 shows the course of feelings during each exposure session. The 2 (Intervention) x 5 (Session) x 7 (Time) repeated measures MANOVA test on the course of feelings showed significant main effects for Intervention, $F(1,20)=6.8, p=0.017, \eta^{2}=0.25$, Session, $F(4,80)=20.0, p<0.001, \eta^{2}=0.5$, and Time, $F(6,120)=12.0$, $p<0.001, \eta^{2}=0.38$. The main effects were superseded by a significant Session $\times$ Intervention interaction, $F(4,80)=3.3$, $p=0.015, \eta^{2}=0.14$, a significant Time $\times$ Intervention interaction, $F$ $(6,120)=11.1, p<0.001, \eta^{2}=0.36$, and a significant Intervention $\times$ Session $\times$ Time interaction, $F(24,480)=2.9, p<0.001, \eta^{2}=0.13$. The significant interaction effects indicate a differential course of feelings during both types of exposure. Further analyses compared the feelings at minute 0,15 and 30 within each session for each intervention separately (see Table 2). The positive exposure induced an increase of positive feelings within all exposure sessions: all sessions showed significant increases in positive feelings between minute 0 and 15 as well as between minute 15 and 30. The negative exposure shows an interesting development of feelings: negative exposure induced a deterioration of feelings within session 1 and 2, within $15 \mathrm{~min}$. The feelings did not improve between minute 15 and 30 in session 1 and 2 . In session 3, feelings also worsened significantly during the exposure but half-way (minute 15-30) they started to improve and at the end of the session they were significantly better than half-way and again at about the same level as at the start of the session. In session 4 and 5 feelings did not change in the first 15 min but they significantly improved in the second half of the exposures. It is concluded that positive exposure makes body dissatisfied people feel significantly better from the beginning till the end. The negative exposure initially induces a worsening of feelings during the first three sessions, but feelings do not get worse and significantly improve during repeated sessions of negative exposure.

\subsection{Process of change: Perceived attractiveness of extremely evaluated body parts}

The perceived attractiveness of one's self-identified most attractive and most unattractive body part were rated at baseline, after each session, at post-test and at follow-up. However, for five participants body part ratings from the first two sessions were 
SESSION 1

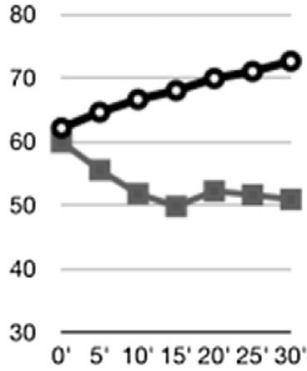

SESSION 2

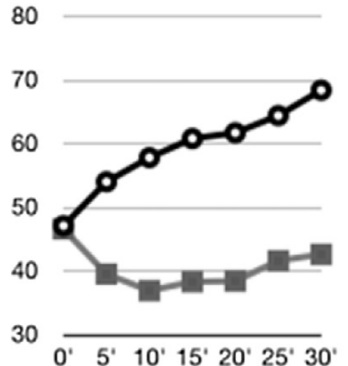

SESSION 3

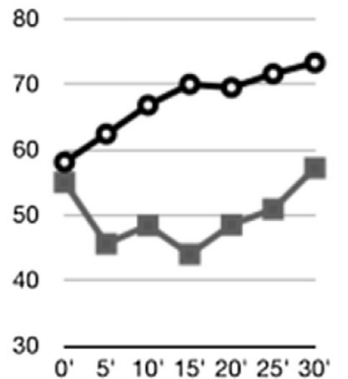

SESSION 4

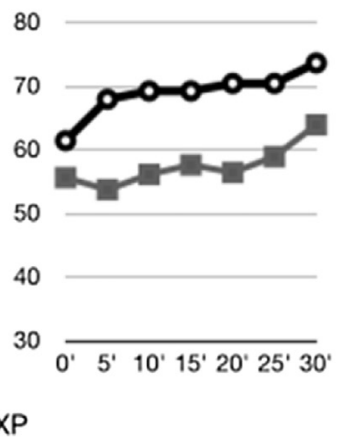

SESSION 5

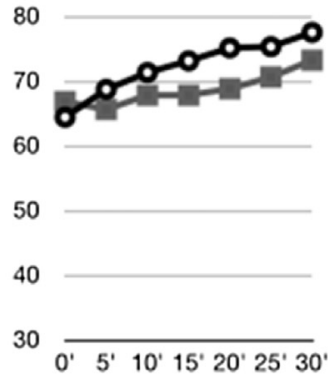

POS EXP

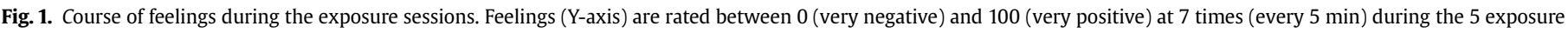

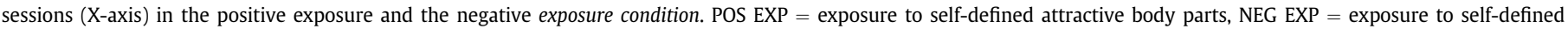
unattractive body parts.

Table 2

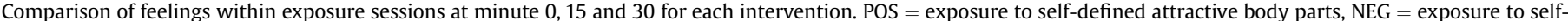
defined unattractive body parts. ${ }^{*} \mathrm{p}<0.05,{ }^{* *} \mathrm{p} \leq 0.01,{ }^{* * *} \mathrm{p} \leq 0.001,{ }^{*} \mathrm{p} \leq 0.06,{ }^{\# \#} \mathrm{p}=0.08$.

\begin{tabular}{|c|c|c|c|c|c|}
\hline Exposure/session & Minute 0 & Minute 15 & Minute 30 & $\begin{array}{l}0^{\prime} \text { vs. } 15^{\prime} \\
\mathrm{t}(10)\end{array}$ & $\begin{array}{l}15^{\prime} \text { vs. } 30^{\prime} \\
\mathrm{t}(10)\end{array}$ \\
\hline POS 1 & $62.2(11.7)$ & $68.1(13.0)$ & $72.7(14.7)$ & $2.7^{*}$ & $3.1^{*}$ \\
\hline POS 2 & $47.1(18.4)$ & $60.8(16.4)$ & $68.4(14.4)$ & $5.6^{* * *}$ & $3.7^{* *}$ \\
\hline POS 3 & $58.1(18.0)$ & $69.96(16.1)$ & $73.3(14.7)$ & $5.9 * * *$ & $1.9^{\# \#}$ \\
\hline POS 4 & $61.4(19.2)$ & $69.2(19.1)$ & $73.6(15.1)$ & $4.9^{* * *}$ & $2.6^{*}$ \\
\hline POS 5 & $64.4(17.8)$ & $73.1(14.7)$ & 77.5 (12.7) & $4.5^{* * *}$ & $2.2^{\#}$ \\
\hline NEG 1 & $59.96(11.5)$ & $49.9(10.8)$ & $51.0(12.6)$ & $2.1^{\#}$ & 0.5 \\
\hline NEG 2 & $46.6(12.0)$ & $38.3(14.4)$ & 42.6 (16.9) & $3.2^{* *}$ & 1.8 \\
\hline NEG 3 & $55.0(13.4)$ & $44.0(11.7)$ & $57.2(12.8)$ & $2.7^{*}$ & $4.3^{* *}$ \\
\hline NEG 4 & $55.6(10.4)$ & $57.6(12.8)$ & $63.9(15.5)$ & 0.8 & $5.5^{* * *}$ \\
\hline NEG 5 & $66.8(13.95)$ & $67.8(14.5)$ & $73.2(12.2)$ & 0.5 & $3.7^{* *}$ \\
\hline
\end{tabular}

missing which made us decide to only analyse the changes from baseline to post-test to follow-up. ${ }^{1}$ For one participant (positive exposure), the pre-test and follow-up data were missing, she was excluded from the analysis. For three other participants ( 1 in positive exposure, 2 in the negative exposure) the pre-test was missing, their pre-test scores were replaced by the mean of the pretest scores of all other participants. Fig. 2 shows the course of perceived attractiveness of the self-identified most attractive body part and the self-identified most unattractive body part.

The 2 (Intervention: positive vs. negative exposure) x 3 (Time: pre vs. post vs. follow up) x 2 (Body Part: most attractive vs. most unattractive) repeated measures ANOVA was conducted to test the intervention effect on perceived attractiveness of one's self-defined most attractive and most unattractive body part.

The ANOVA showed a significant Intervention $\times$ Time $\times$ Body Part interaction, $F(2,18)=7.49, p=0.004, \eta^{2}=0.45$, indicating a differential change of body part attractiveness over time in both types of exposure. The significant main effects of Time, $F(2$, $38)=14.8, p<0.001, \eta^{2}=0.44$, and Body Part, $F(1,19)=190.5$, $p<0.001, \eta^{2}=0.91$, were superseded by a significant Body Part $\times$ Time interaction, $F(2,38)=10.3, p<0.001, \eta^{2}=0.35$, indicating differential effects of body part attractiveness ratings over time, and by a significant Body Part $\times$ Intervention interaction, $F(1,19)=9.9, p=0.005, \eta^{2}=0.34$, indicating that the interventions had a differential effect on the attractiveness ratings of body parts. Further analyses showed no differences between interventions in

\footnotetext{
${ }^{1}$ Analysis of all data over all sessions with a replacement of missing values by a mean rating for the intervention did not substantially change the results and conclusions. Also, analysis of the data without these 5 participants did not substantially change the results and conclusions.
}

attractiveness ratings of the attractive $(\mathrm{F}(1,20)=0.3$, NS) and the unattractive $(F(1,20)=1.2$, NS) body part at pre-measure. The postmeasure did however show significant differences between interventions in perceived attractiveness of the attractive ( $\mathrm{F}$ $(1,20)=18.6, p<0.001)$ and the unattractive $(F(1,20)=10.0$, $p=0.005$ ) body part. The data show that the most unattractive body part was perceived as significantly more attractive after negative exposure $(\mathrm{M}=48.4, \mathrm{SD}=24.3)$ compared to positive exposure $(M=18.1, S D=16.8)$. The most attractive body part was perceived as significantly more attractive after positive exposure $(\mathrm{M}=92.8, \mathrm{SD}=6.1)$ compared to negative exposure $(\mathrm{M}=79.2$, $\mathrm{SD}=8.8$ ). The follow up measures show no differences between interventions in the perceived attractiveness of the attractive body part $(\mathrm{F}(1,19)=2.0$, NS). However, there was still a marginal difference in perceived attractiveness of the unattractive body part $(\mathrm{F}$ $(1,19)=3.4, p=0.08)$ at follow up; the unattractive body part was still perceived to be significantly more attractive in the negative exposure intervention.

\section{Discussion}

The present study shows that body exposure is effective in increasing body satisfaction and leads to less body checking, less body avoidance, less body concerns and better mood. Contrary to expectations, both types of exposure were effective in increasing body satisfaction and mood, with no detected differences between both interventions at post-test. Improvements for body satisfaction and mood were maintained at follow-up while body shape concerns and body checking still improved between post-test and follow-up. Body avoidance improvements were maintained for the positive exposure while the negative exposure tended to further decrease long-term body avoidance at follow-up. 


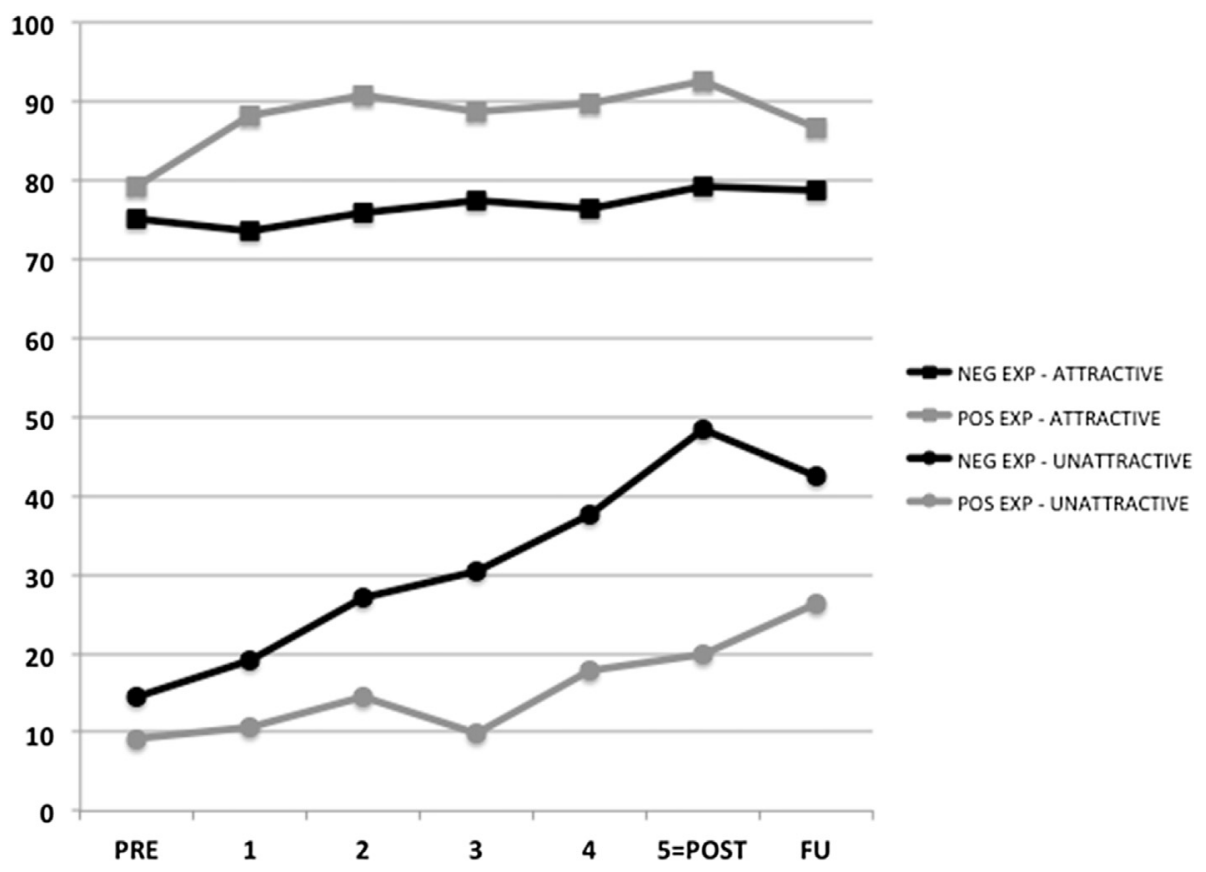

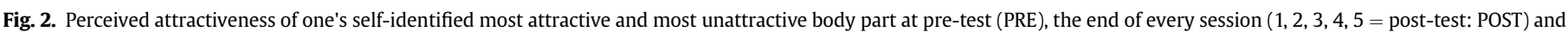

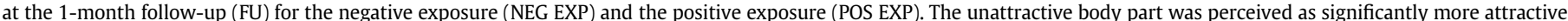

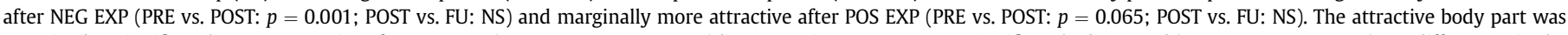

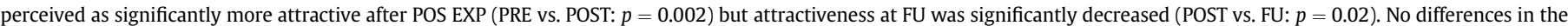
perceived attractiveness of the attractive body part were found after NEG EXP (PRE vs. POST: NS; POST vs. FU: NS).

The course of feelings during exposure shows that the positive exposure intervention mainly induced positive feelings; participants felt increasingly good during the positive exposure and better after the exposure compared to before. The negative exposure intervention induced a worsening of feelings during the first two sessions but feelings started to improve during repeated sessions of negative exposure. After four sessions of 30 exposure minutes the differences in state feelings between both conditions had largely disappeared. Clearly, the worsening of feelings during the negative exposures discontinues after a couple of exposure sessions and is replaced by mood improvement with repeated exposures. It is not clear what would have happened when the exposure sessions were longer. The current sessions only lasted $30 \mathrm{~min}$ which is short for exposure treatment. The exposure sessions might have been too short for the recovery of affect within sessions in especially the negative exposure, while longer exposure sessions possibly might allow the habituation/exposure effects to be expressed sooner.

One might however also question whether the emotionally more difficult negative exposure, at least in the beginning, is necessary to do, since the positive exposure was effective as well. The negative exposure might increase the risk of people dropping out of treatment, especially in the early sessions. However, the negative exposure led to a significantly better appraisal of the body part that is perceived to be the most unattractive, suggesting that prolonged attention for a most loathed body part is able to change its negative valence into a more positive valence. This increase in attractiveness is smaller after positive exposure during which the most unattractive body part is not attended, implying that negative exposure is a valuable part of body image treatment. The findings show that body parts that are attended during the exposure (the unattractive parts in the negative exposure and the attractive parts in the positive exposure) are rated more attractive at post measures than body parts that are not attended during the exposure (the attractive parts in the negative exposure and the unattractive parts in the positive exposure), though the marginally significant increase in attractiveness of the most loathed body part in the positive exposure condition suggests that there is some generalisation of increased attractiveness to body parts one was not directly attending. Further, negative exposure might be more effective than positive exposure in reducing longer-term body image avoidance, which could be necessary for negative body-related feelings to extinguish.

A limitation of the present study is the small sample size. Though the results are robust, the sample size is small, so these findings need replication in larger trials. Another limitation is the use of a non-clinical sample. Though body dissatisfaction was high in this sample, we should be careful to generalise the results to clinical practice. The current data indicate that negative exposure is more effective in increasing the attractiveness of body parts that are perceived as extremely unattractive but they also demonstrate that positive exposure is more easy to do. Adding positive exposure to negative exposure might make body exposure more feasible in general, which could help to prevent drop out from exposure treatment.

From a more theoretical point, it is still unclear why body exposure leads to an increase in body satisfaction. Recent extinction models (e.g., Craske, Treanor, Conway, Zbozinek, \& Vervliet, 2014) stress that effective exposures aim at inhibitory learning, meaning that one learns to disconfirm the original association between a conditioned stimulus (CS) and an unconditioned stimulus (US). If the body is considered the CS predicting the occurrence of bodyrelated negative thinking and body loathing (US) (Jansen et al., 2008), exposure should inhibit this association by the formation of a new association: if CS, no US (inhibitory learning). Extinction thus aims to disconfirm the belief that the CS predicts the US. It requires lots of practice (exposures) to change the predominant and automatic US popping up and to get it replaced by a new US (e.g., positive evaluations). An exposure is effective when confrontation with the CS elicits the newly associated US and not the old US. In the positive exposure condition it could indeed have been learned 
that the CS might as well predict another US, e.g. positive thoughts and feelings. However, during the negative exposure, participants did experience their 'old' US intensely; they did not actively work on a disconfirmation of the negative thinking and feeling that was elicited by seeing their bodies, but their body satisfaction increased as well. It could be that they 'discovered' or experienced during the exposure that the body was less miserable than presumed, that they changed the mental representation of the body and disconfirmed the original CS - US association in a more implicit way. The attractiveness ratings of the most unattractive body part indirectly support this idea and this hypothesis could be tested in future studies by e.g., studying self-talk during negative exposure or implicit negative associations with the own body. Knowledge about the mechanism of why body exposure works enables the translation of these experimental findings into clinical extinction interventions that effectively tackle the mechanisms maintaining body loathing.

\section{Conclusions}

This study shows that 5 sessions of $30 \mathrm{~min}$ exposure to one's body using a mirror increases body satisfaction in body dissatisfied young women. Both the exposure to body parts that are evaluated as most unattractive body parts ('negative exposure') and the exposure to body parts that are evaluated as most attractive body parts ('positive exposure') are effective in increasing body satisfaction and reducing depressive symptoms. Positive exposure induces positive feelings from the start to the end while negative exposure initially induces a worsening of feelings but feelings improve during repeated sessions of negative exposure. Negative exposure leads to a significantly stronger increase of perceived attractiveness of the most loathed body part than positive exposure.

\section{Acknowledgements}

All authors declare that there is no conflict of interest.

\section{References}

Beck, A. T., Steer, R. A., \& Brown, G. K. (2002). Beck depression inventory. Dutch translation: van der Does, A.J.W. (2002). Manual for the Dutch BDI-II (2nd ed.). San Antonio, TX/Lisse, NL: The Psychological Corporation/Swets Test Publisher.
Bouman, T. (1999). Mijn Uiterlijk (My looks). Unpublished questionnaire to identify body dissatisfaction. The Netherlands: Dept. of Clinical Psychology, Groningen University.

Craske, M. G., Treanor, M., Conway, C. C., Zbozinek, T., \& Vervliet, B. (2014). Maximizing exposure therapy: an inhibitory learning approach. Behaviour Research and Therapy, 58, 10-23.

Delinsky, S. S., \& Wilson, G. T. (2006). Mirror exposure for the treatment of body image disturbance. International Journal of Eating Disorders, 39, 108-116.

Evers, A., Vliet-Mulder, J. C. van, \& Groot, C. J. (2005). Documentatie van tests en testresearch in Nederland, aanvulling 2005/01 (COTAN). Amsterdam: Boom test uitgevers.

Fairburn, C. G., \& Beglin, S. J. (1994). The assessment of eating disorders: interview or self-report questionnaire? International Journal of Eating Disorders, 16, $363-370$.

Hilbert, A., Tuschen-Caffier, B., \& Vögele, C. (2002). Effects of prolonged and repeated body image exposure in binge-eating disorder. Journal of Psychosomatic Research, 52, 137-144.

Hildebrandt, T., Loeb, K., Troupe, S., \& Delinsky, S. (2012). Adjunctive mirror exposure for eating disorders: a randomized controlled pilot study. Behaviour Research and Therapy, 50, 797-804.

Jansen, A., Bollen, D., Tuschen-Caffier, B., Roefs, A., Tanghe, A., \& Braet, C. (2008) Mirror exposure reduces body dissatisfaction and anxiety in obese adolescents: a pilot study. Appetite, 51, 214-217.

Jansen, A., Nederkoorn, C., \& Mulkens, S. (2005). Selective visual attention for ugly and beautiful body parts in eating disorders. Behaviour Research and Therapy, 43, 183-196.

Johnson, F., \& Wardle, J. (2005). Dietary restraint, body dissatisfaction, and psychological distress: a prospective analysis. Journal of Abnormal Psychology, 114, $119-125$.

Key, A., George, C. L., Beattie, D., Stammers, K., Lacey, H., \& Waller, G. (2002). Body image treatment within an inpatient program for anorexia nervosa: the role of mirror exposure in the desensitization process. International Journal of Eating Disorders, 31, 185-190.

Luethcke, C. A. McDaniel, L. \& Becker, C. B. (2011). A comparison of mindfulness, nonjudgmental, and cognitive dissonance-based approaches to mirror exposure. Body Image, 8, 251-258.

Moreno-Domínguez, S., Rodríguez-Ruiz, S., Fernández-Santaella, M. C., Jansen, A., \& Tuschen-Caffier, B. (2012). Pure versus guided mirror exposure to reduce body dissatisfaction: a preliminary study with university women. Body Image, 9, 285-288.

Reas, D. L., Whisenhunt, B. L., Netemeyer, R., \& Williamson, D. A. (2002). Development of the body checking questionnaire: a self-report measure of body checking behaviors. International Journal of Eating Disorders, 31, 324-333.

Rosen, J. C., Strebnik, D., Saltzberg, E., \& Wendt, S. (1991). Development of a body image avoidance questionnaire. Psychological Assessment: A Journal of Consulting and Clinical Psychology, 3, 32-37.

Smeets, E., Jansen, A., \& Roefs, A. (2011). Bias for the (un)attractive self: on the role of attention in causing body (dis)satisfaction. Health Psychology, 30, 360-367.

Stice, E., \& Shaw, H. E. (2002). Role of body dissatisfaction in the onset and maintenance of eating pathology. A synthesis of findings. Journal of Psychosomatic Research, 53, 985-993.

Trentowska, M., Svaldi, J., \& Tuschen-Caffier, B. (2014). Efficacy of body exposure as treatment component for patients with eating disorders. Journal of Behavior Therapy and Experimental Psychiatry, 45, 178-185.

Van der Does, A. J. W. (2002). BDI-II-NL. Handleiding (Manual). De Nederlandse versie van de (The Dutch version of the) Beck depression inventory (2nd ed.). Lisse: Harcourt Test Publishers. 